\title{
Natural radioactivity in aerosols collected in a NORM Industry: Radiological implications
}

\author{
E.G. San Miguel' ${ }^{1}$, J.P. Bolívar ${ }^{1}$ and R. García-Tenorio ${ }^{2}$ \\ ${ }^{1}$ Dpto Física Aplicada, Facultad Ciencias Experimentales, Universidad de Huelva, \\ 21071 Huelva, Spain \\ ${ }^{2}$ Dpto Física Aplicada II, E.T.S. Arquitectura, Universidad de Sevilla, 41012 Sevilla, Spain \\ e-mail: gtenorio@us.es
}

\begin{abstract}
On the frame of a broad project devoted to the evaluation of the occupational and environmental radiological impact of several NORM industries located at the South-West Spain, a study determining the U-series radionuclides levels in air particulate matter has been accomplished inside a phosphate rock processing plant dedicated to phosphoric acid production. U-series radionuclides concentrations in aerosols collected inside this plant have been determined and compared with those obtained in aerosols collected from a reference monitoring station not affected by NORM industries or other anthropogenic inputs. Additionally, based on the observed increments in the volumetric concentrations of the radionuclides from the U-series in the plant, the increase in the occupational doses due to inhalation for their workers has been estimated. Even under conservative assumptions, the dose enhancements are clearly below $1 \mathrm{mSv} / \mathrm{year}$, the annual limit for the public.
\end{abstract}

\section{INTRODUCTION}

The law regulations concerning radioactivity have suffered a trend to minimize the dose limits received by both population (non-occupational) and workers (occupational). The situation of many industries and their associated wastes involved in the management of NORM (Naturally Occurring Radioactive Materials) has to be evaluated to guarantee the safety of the population and workers. NORM is defined as all naturally occurring radioactive materials where human activities have increased the potential risk for radiation exposure in comparison to the unaltered situation. A well-known example of NORMrelated processes is that of the facilities devoted to the production of phosphoric acid and phosphate fertilizers. In these industries are manufactured as raw material phosphate rock, which can contain high concentrations of radionuclides from ${ }^{238} \mathrm{U}$-Series, up to 100 times higher than in an average soil [1].

A large chemical complex is located in the southwest of Spain, close to the city of Huelva. This complex includes several plants dedicated to the extraction of $\mathrm{Cu} / \mathrm{Fe}$ and to the production of $\mathrm{H}_{2} \mathrm{SO}_{4}$, an oil refinery and two phosphate rock processing factories with several plants working in parallel $[2,3]$. On the frame of a project on the evaluation of the occupational and environmental radiological impact of several NORM industries located at the South of Spain, a study determining the U-series radionuclides levels in air particulate matter has been accomplished inside one of the phosphate rock processing plants dedicated to phosphoric acid production where phosphate rock enriched in radionuclides from the U-series are treated. This phosphoric acid is the basis for the production of phosphate fertilizers. U-series radionuclides concentrations in aerosols collected inside the selected plant have been compared with those obtained in aerosols from a reference monitoring station not affected by NORM industries. The obtained information has been the basis for the estimation under conservative assumptions of the occupational doses in the analysed plant due to inhalation. 


\section{MATERIALS AND METHODS}

\subsection{Sampling procedures}

The samplings were performed with high volume samplers $\left(40 \mathrm{~m}^{3} \mathrm{~h}^{-1}\right)$ with Total Suspended Particles (TSP) inlets, using QF20 Schleicher and Schuell quartz fibre filters and taken one sample every fifteen days with time sampling of 48 hours. Two sampling points were elected (Figure 1): one in an open air representative area of the phosphate processing plant $\left(37^{\circ} 13^{\prime} 51.47^{\prime \prime} \mathrm{N} ; 6^{\circ} 56^{\prime} 57.45^{\prime \prime} \mathrm{W}\right)$, and the other in a remote area to serve as reference point $\left(37^{\circ} 6^{\prime} 14.15^{\prime \prime} \mathrm{N} ; 6^{\circ} 44^{\prime} 3.24^{\prime \prime} \mathrm{W}\right)$. The bulk TSP levels collected were determined in both cases by weighting the filters using standard procedures. The sampling campaign covered a period of six months.

\subsection{Radionuclide measurements}

The majority of the radionuclides with long half-lives of the $\mathrm{U}$ and Th series ( $\mathrm{U}$ and Th-isotopes, ${ }^{210} \mathrm{~Pb}$ and ${ }^{210} \mathrm{Po}$ ) have been determined in the collected filters.

\subsubsection{Alpha particle spectrometry}

For the determination of $\mathrm{U}$ and Th-isotopes as well as ${ }^{210} \mathrm{Po}$ in the samples, a sequential radiochemical method was applied. In this method, $\mathrm{U}$ and Th-isotopes are electrodeposited onto stainless steel planchets while ${ }^{210} \mathrm{Po}$ is self-deposited onto silver disks after its isolation. The whole procedures can be seen elsewhere [4-6]. Typical recovery yields of 60-80\% were obtained.

The U, Th, and Po planchets were measured using an EG\&G Ortec alpha spectrometry system equipped with $450 \mathrm{~mm}^{2}$ ion-implanted silicon detectors. Counting times ranged from two days to one week, depending on the activity concentrations and the recovery obtained in the chemical separation.

\subsubsection{Gamma spectrometry}

${ }^{210} \mathrm{~Pb}$ and ${ }^{7} \mathrm{Be}$ have been determined through gamma-ray spectrometry through their $46.5(4.05 \%)$ and $477.6 \mathrm{keV}(10.43 \%)$ photon emissions respectively. ${ }^{7} \mathrm{Be}$ was determined in the collected filters for supporting some conclusions obtained in the analysis of the ${ }^{210} \mathrm{~Pb}$ data.

Gamma measurements were performed using an XtRa coaxial Ge detector (Canberra), with 38\% relative efficiency and FWHM of $0.95 \mathrm{keV}$ at the $122 \mathrm{keV}$ line of ${ }^{57} \mathrm{Co}$ and $1.9 \mathrm{keV}$ at the $1333 \mathrm{keV}$ line of ${ }^{60} \mathrm{Co}$. The detector was attached to a conventional electronic chain, including a multichannel analyser, and was shielded with $\mathrm{Fe} 15 \mathrm{~cm}$ thick. Furthermore, the detector with its shielding is located in a room with walls and ceiling made of $75 \mathrm{~cm}$ thick concrete in the ground of a four plants building. The efficiency calibration of the gamma spectrometric system can be seen elsewhere [7].

\subsection{Doses assessment methodology}

The occupational committed effective doses due to inhalation have been derived from the average concentration of the radionuclides in air through the following equation:

$$
D_{i n h, i}=C_{i} \cdot F_{i n h} \cdot T \cdot B \cdot D F_{\text {inh }, i}
$$

where: $D_{i n h}$, is the commited effective dose to the critical group by inhalation of radionuclide $i\left(\mathrm{~Sv} \mathrm{y}^{-1}\right)$; $C_{i}$ is the concentration of radionuclide $i$ in air $\left(\mathrm{Bq} \mathrm{m}^{-3}\right) ; F_{\text {inh }}$ is the inhalable fraction of the aerosol (assumed to be 1); $T$ is the occupational factor for the affected workers $\left(\mathrm{h}^{-1}\right) ; B$ is the air inhalation rate of the critical group $\left(\mathrm{m}^{3} \mathrm{~h}^{-1}\right)$, and $D F_{i n h, I}$ is the dose factor for inhalation of radionuclide $i$ for the critical group $\left(\mathrm{Sv} \mathrm{Bq}^{-1}\right)$ (dose factors taken from [1]). A conservative estimation of $T$ has been done 
for the workers of the phosphate rock processing plant: 300 days of work per year and 8 hour of stay in the area per day, i.e. $T=2400 \mathrm{hy}^{-1}$.

\section{RESULTS AND CONCLUSIONS}

The results obtained for ${ }^{238} \mathrm{U},{ }^{234} \mathrm{U},{ }^{230} \mathrm{Th}$ and ${ }^{210} \mathrm{~Pb}$ for the analysed air particle matter samples have allowed us to reach similar conclusions in relation with the planned objectives, with independence of the radionuclide from the Uranium series considered. For that reason, in this paper only especial emphasis to the results of one of them, ${ }^{210} \mathrm{~Pb}$, is given.

Figure 2 shows particulate matter concentration in aerosol filters from both sampling sites; phosphate rock processing plant (Fertiberia) and the reference site (INTA). As it can be observed in this Figure particulate matter concentrations in Fertiberia presents clear enhancements in relation to the background values determined in the reference site.

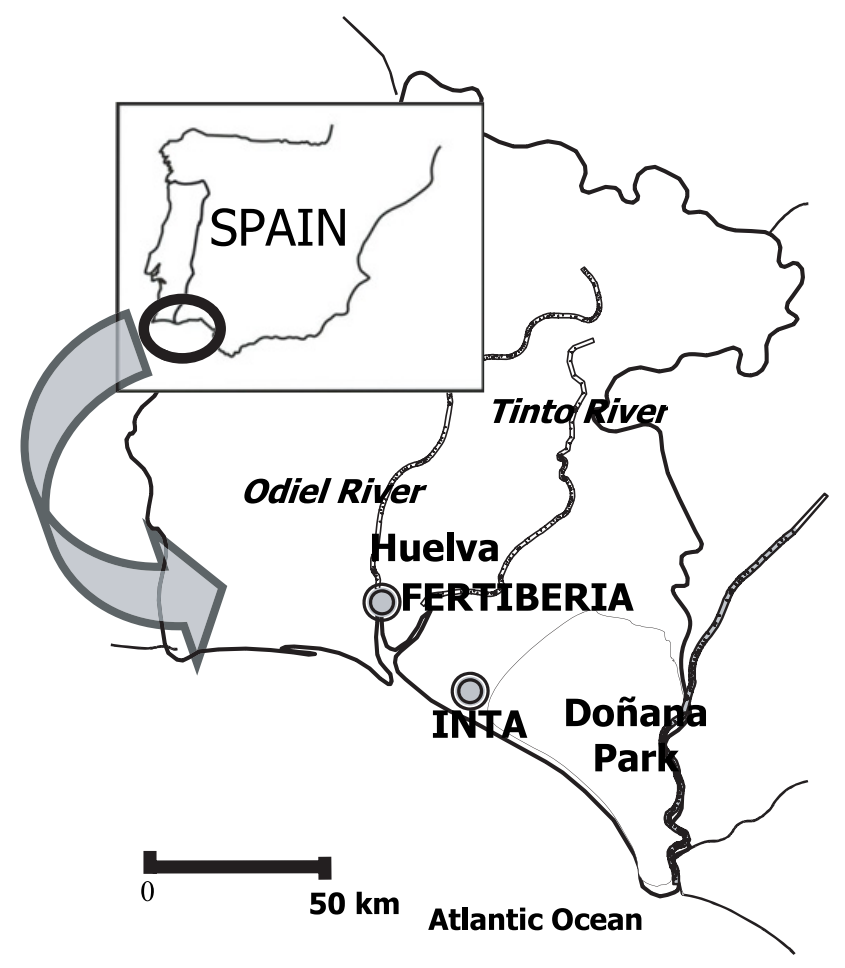

Figure 1. Map showing location of sampling stations.

The average bulk concentration for Total Suspended Particle (TSP) in the phosphate rock plant $\left(414 \pm 40 \mu \mathrm{g} \mathrm{m}^{-3}\right)$ is one order of magnitude (twenty times) higher than those ones from reference site $\left(26 \pm 3 \mu \mathrm{g} \mathrm{m}^{-3}\right)$. The increase in the particulate matter concentrations detected in the atmosphere of Fertiberia can be due to different causes related with the working activities carried out in the plant: milling of the rock, resuspension of previously deposited dust, etc., and its anthropogenic origin can be inferred from the data shown in Figure 3. The average massic ${ }^{210} \mathrm{~Pb}$ concentrations in Fertiberia (phosphate rock plant) of $3.0 \pm 0.5 \mathrm{kBq} \mathrm{g}^{-1}$ are clearly lower than the determined ones in the reference site $\left(24 \pm 3 \mathrm{kBqg}^{-1}\right)$. This data indicates the presence of non-natural material in the phosphate rock plant air with ${ }^{210} \mathrm{~Pb}$ levels clearly lower than the existing ones in the natural particulate matter. 


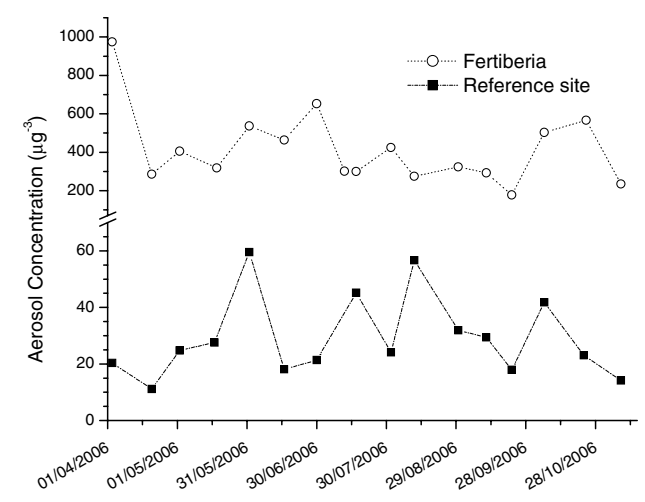

Figure 2. Particulate matter concentrations $\left(\mu \mathrm{g} \mathrm{m}^{-3}\right)$ in Phosphate rock processing plant (Fertiberia) and in the reference site.

However, the extra anthropogenic particulate matter existing in the atmosphere of Fertiberia is supplying extra amounts of ${ }^{210} \mathrm{~Pb}$, as can be deduced also from Figure 3, by comparing the ${ }^{210} \mathrm{~Pb}$ volumetric concentrations determined in the phosphate rock plant and in the reference site. An average increment in the ${ }^{210} \mathrm{~Pb}$ concentration of about $0.24 \mathrm{mBq} \mathrm{m}^{-3}$ has been determined in the processing plant, corresponding to the average observed increment of $387 \mu \mathrm{g} \mathrm{m}^{-3}$ in the bulk particulate material collected in the filters. This data lead us to estimate that the extra material collected in the filters from Fertiberia has an average ${ }^{210} \mathrm{~Pb}$ mass concentration of $615 \mathrm{mBqg}^{-1}$, value which is similar to those determined in the waste produced in huge amounts in the plant (phosphogypsum) and of the same order of magnitude than $\mathrm{U}$-series radionuclides concentrations in the phosphate rock used as raw material $\left(1-1.5 \mathrm{Bqg} \mathrm{g}^{-1}\right)$.

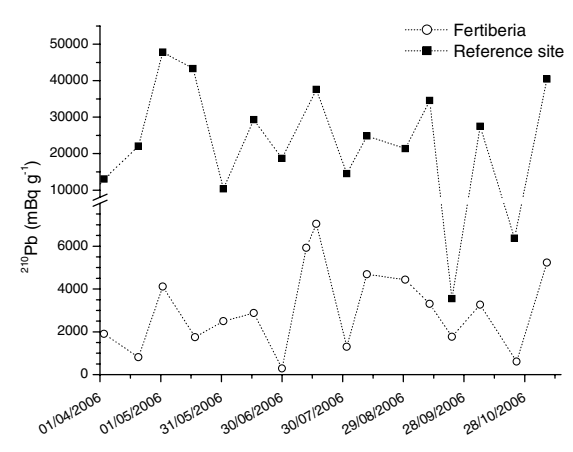

a)

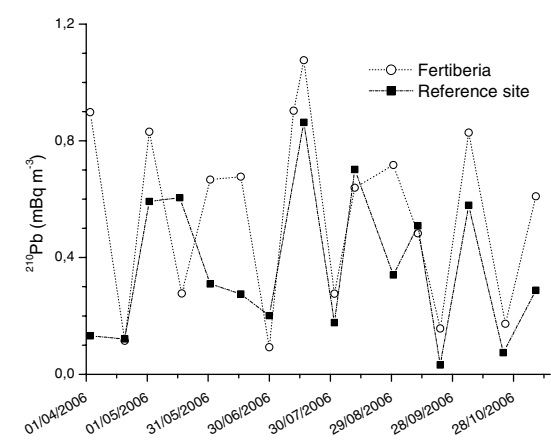

b)

Figure 3. ${ }^{210} \mathrm{~Pb}$ activities per unit mass $\left(\mathrm{mBq} \mathrm{g}^{-1}\right)$ (Fig. a) and per unit volume $\left(\mathrm{mBq} \mathrm{m}^{-3}\right)$ (Fig. b) in both sampling points.

The main conclusions derived from the analysis of the ${ }^{210} \mathrm{~Pb}$ data are confirmed by analysing the ${ }^{7} \mathrm{Be}$ results. The average concentration per unit mass of ${ }^{7} \mathrm{Be}$, radionuclide with an exclusive cosmogenic origin, is one order of magnitude lesser than in the reference site (see Figure 4), reaffirming the presence in the processing plant of anthropogenic amounts of particulate matter. Nevertheless, the mentioned nonnatural particulate matter in the atmosphere of Fertiberia is free of ${ }^{7} \mathrm{Be}$ as can be observed from Figure 4. The activity concentrations per unit of volume in the processing plant are comparable to those obtained in the reference site. For this reason, the influence of the industrial activity can be inferred from the 
${ }^{210} \mathrm{~Pb}$ levels, indicating the previously mentioned origins of the extra particulate matter in the air of the plant, but not in the ${ }^{7} \mathrm{Be}$ levels.

Based on the previous gained information, a conservative estimation of the additional committed effective doses for occupational workers due to inhalation of the anthropogenic material present in the environment of the Fertiberia plant has been done.

Several assumptions have been made to estimate the doses: a) the concentration of the anthropogenic extra material in the atmosphere of the plant is $400 \mu \mathrm{g} \mathrm{m}^{-3}$, and b) based on the gamma and alpha particle spectrometry results, U-series radionuclides activity concentrations in the aerosol particulate anthropogenic matter are considered as $1.5 \mathrm{~Bq} \mathrm{~g}^{-1}$ (with all the members of the series in secular equilibrium), the same as that in the phosphate rock used in the factory. In this way the increase in activity concentration of $\mathrm{U}$-series radionuclides gives $6 \cdot 10^{-4} \mathrm{Bqm}^{-3}$. (The ${ }^{238} \mathrm{U},{ }^{234} \mathrm{U}$ and ${ }^{230} \mathrm{Th}$ results determined in the air filters by alpha-particle spectrometry together with the shown ${ }^{210} \mathrm{~Pb}$ data support this hypothesis).

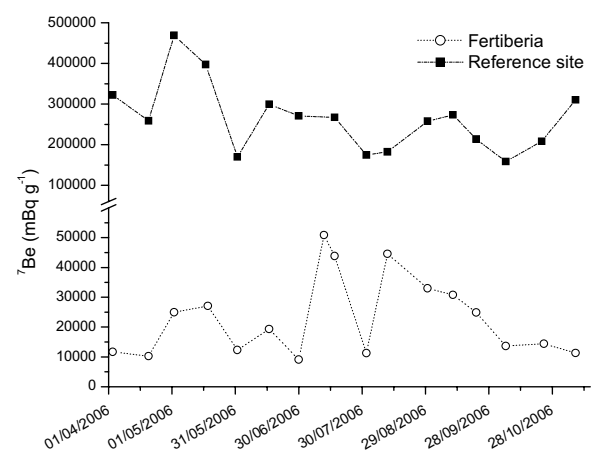

a)

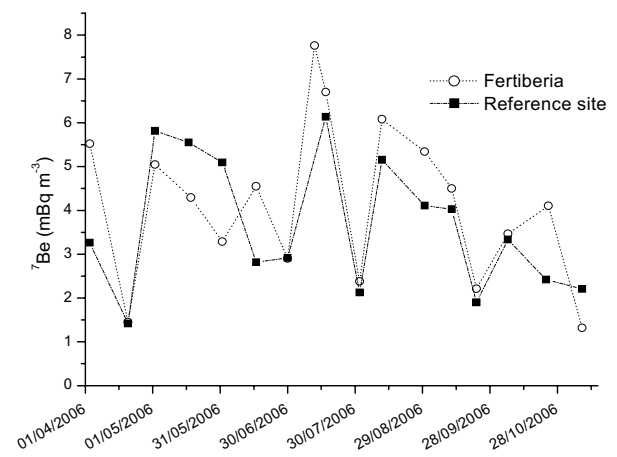

b)

Figure 4. ${ }^{7} \mathrm{Be}$ activities per unit mass (Fig. a) and per unit volume (Fig. b) in both sampling points.

Dose calculations have been accomplished, as indicated in the materials and methods section, for three different inhalation rate cases, assuming either that the worker is sited $\left(B=0.54 \mathrm{~m}^{3} \mathrm{~h}^{-1}\right)$, or doing light exercise $\left(B=1.5 \mathrm{~m}^{3} \mathrm{~h}^{-1}\right)$ or doing heavy exercise $\left(B=3 \mathrm{~m}^{3} \mathrm{~h}^{-1}\right)$ [8]. Under these assumptions, the calculated committed effective dose due to inhalation were $0.02 \mathrm{mSv} \mathrm{y}^{-1}, 0.05 \mathrm{mSv}$ $\mathrm{y}^{-1}$ and $0.12 \mathrm{mSv}^{-1}$ respectively. These values are clearly lower than the annual limit for the public $\left(1 \mathrm{mSv}^{-1}\right)$, being consequently not demanding the adoption of radiological protection measures due to the inhalation pathway in the analysed phosphate rock plant.

\section{Acknowledgments}

This research has been supported by the Spanish Nuclear Safety Council, and also by the Andalusian Regional Government through the project of excellence "Origin, Characterization and Prediction of Surface $\mathrm{O}_{3}$ atmospheric contamination episodes in west Andalusia". The laboratory work carried out by Antonio Padilla is specially acknowledged.

\section{References}

[1] United Nations Scientific Commitee on the Effects of Atomic Radiation (UNSCEAR). Sources and effects of Ionizing Radiation. Report to the General Assembly with Scientific Annexes, United Nations, Volume I, 2000.

[2] J.P. Bolívar, R. García-Tenorio and F. Vaca, Water Research 34, 2941 (2000). 
[3] J.P. Bolívar, R. García-Tenorio, J.L. Más and F. Vaca, Environment International 27, 639 (2002).

[4] E. Holm and R. Fukai, Talanta 24, 659 (1977).

[5] Aguado, J., Aplicaciones de la espectrometría alfa en la caracterización de isótopos de Ra y U en residuos industriales y matrices ambientales (Univ. de Sevilla, Sevilla, 2003). In Spanish.

[6] F. El-Daoushy, K. Olsson and R. García-Tenorio, Hydrobiologia 214, 43 (1991).

[7] F. Martínez-Ruiz, E. Borrego, E.G. San Miguel and J.P. Bolívar, Nucl. Inst. Meth. A 580, 663 (2006).

[8] Human respiratory tract model for radiological protection. ICRP Publication 66. Annals of the ICRP $24(1-3)$. 